\title{
Effects of minocycline and tetracycline on the vaginal yeast flora
}

\author{
J. D. ORIEL AND PAMELA M. WATERWORTH
}

From the Departments of Genito-Urinary Medicine and Microbiology, University College Hospital, London

SYNOPSIS Two groups of women with non-specific genital infection were treated for two weeks with tetracycline $250 \mathrm{mg}$ six-hourly and minocycline $100 \mathrm{mg}$ twice daily respectively. Cultures for yeasts were performed before treatment and at the end of the first and second weeks. Before treatment yeasts, mostly Candida albicans, were recovered from $13 \%$ of the women. After one and two weeks' treatment yeasts were isolated from 22 and $29 \%$ of women treated with tetracycline, and from 19 and $29 \%$ of women treated with minocycline. It is concluded that despite inhibition of the growth of yeasts shown by minocycline in vitro, there is no evidence of any significant difference between the actions of tetracycline and minocycline on the vaginal yeast flora.

Minocycline is a recently introduced semi-synthetic tetracycline. Unlike other tetracyclines it has been shown to inhibit the growth of Candida albicans in vitro in relatively low concentrations; a disc containing $30 \mu \mathrm{g}$ produces a zone of inhibition about $13 \mathrm{~mm}$ in diameter, though this inhibition is much affected by the composition of the medium (Waterworth, 1974).

It has been known for many years that therapy with tetracyclines may be accompanied by an overgrowth of yeasts, particularly C. albicans, in the intestinal and lower urogenital tracts (Winner and Hurley, 1964). This overgrowth is often asymptomatic but may at times be accompanied by clinical signs such as stomatitis, pruritus ani or vulvovaginitis. The cause is uncertain; the suppression of inhibitory bacteria by tetracyclines may allow the overgrowth of yeasts, or alternatively low concentrations of tetracyclines may directly potentiate yeast replication.

In view of the inhibitory effect shown by minocycline against Candida spp. in vitro it might be hoped that less yeast overgrowth would occur in patients treated with this drug than with other tetracyclines. We have investigated this possibility by comparing the effect of oral tetracycline and minocycline on the vaginal yeast flora.

\section{Subjects and Methods}

The patients studied were women attending the

Received for publication 27 November 1974.
Department of Genito-Urinary Medicine, University College Hospital with the diagnosis of non-specific genital infection (NSGI). They usually came because they were sexual contacts of men with nonspecific urethritis. After excluding infection with Neisseria gonorrhoeae and Trichomonas vaginalis it is our practice to treat these women with a course of a tetracycline.

\section{CLINICAL EXAMINATION}

Patients were examined in the lithotomy position. The external genitalia were inspected and the vagina and cervix examined after the insertion of a Cusco speculum. Vulvovaginitis was defined as vulval or vaginal erythema with or without vulval scaling, oedema or excoriation and with or without the presence of vaginal plaques.

Specimens were collected from patients on first attendance as follows:

1 Cervical and urethral material was spread on glass slides, and culture plates for $N$.gonorrhoeae were inoculated.

2 Vaginal material was suspended in a drop of normal saline and covered with a cover slip; culture medium for $T$. vaginalis was also inoculated.

3 A further vaginal specimen was collected on a cotton wool swab which was broken into $1.0 \mathrm{ml}$ sterile water in a bijou plastic container with a close-fitting cap for yeast culture.

MICROBIOLOGICAL EXAMINATION

Wet preparations were examined immediately for 
$T$. vaginalis. Urethral and cervical smears were stained by Gram's method and examined for intracellular Gram-negative diplococci. Selective culture media were used for the isolation of $N$. gonorrhoeae, and Feinberg-Whittington medium was used for culture of $T$. vaginalis. Cultures for Candida spp. were examined as follows:

The water containing the vaginal swab was well mixed, then a full $4 \mathrm{~mm}$ loopful was transferred to a plate of Sabouraud's medium containing $25 \mu \mathrm{g} / \mathrm{ml}$ chloramphenicol. The inoculum was streaked across the sides of the plate in turn without intervening flaming of the loop. Cultures were incubated overnight at $37^{\circ} \mathrm{C}$. C. albicans was identified by the germ-tube test (Mackenzie, 1962); any yeasts not producing germ-tubes after four hours' incubation in serum were sent to Dr D. W. R. Mackenzie for identification.

\section{TREATMENT}

Women who had gonorrhoea, trichomoniasis or candidal vulvovaginitis which required immediate treatment with an antifungal agent were all excluded from the project. The remainder were assigned at random to one of two treatment groups. Women in the first were given tetracycline $250 \mathrm{mg}$ six-hourly, and in the second, minocycline $100 \mathrm{mg}$ twice daily. Treatment continued for two weeks; patients were re-examined at the end of the first and second weeks and further cultures for Candida were prepared; any side effects of the antibiotics were recorded on each attendance.

\section{Results}

A group of 204 women with NSGI was studied. Before treatment 27 of them (13\%) yielded yeasts on vaginal culture: 24 isolates were $C$. albicans and three were $T$. glabrata. Five of the 27 yeast-positive women and 11 of the 177 yeast-negative women showed vulvovaginitis. Of the 204 women, 99 were treated with tetracycline $250 \mathrm{mg}$ six-hourly and 105 with minocycline $100 \mathrm{mg}$ twice daily. The results were as follows.

\section{TREATMENT WITH TETRACYCLINE}

At the end of the first week of treatment three of the 99 women given tetracycline had stopped taking the drug because of side effects, and 28 had defaulted, leaving 68 patients still available for study. Of these $68,15$ now yielded yeasts on culture ( $22 \%)$; all the isolates were $C$. albicans (table I). Four of the 15 women with positive cultures showed vulvovaginitis, as did two of the 53 women with negative cultures.

After the second week of treatment no more patients had experienced side effects, but a further

\begin{tabular}{|c|c|c|c|}
\hline $\begin{array}{l}\text { Days after } \\
\text { Treatment }\end{array}$ & $\begin{array}{l}\text { No. } \\
\text { Attending }\end{array}$ & $\begin{array}{l}\text { No. with Positive } \\
\text { Cultures }\end{array}$ & $\%$ Positive \\
\hline $\begin{array}{r}0 \\
7 \\
14\end{array}$ & $\begin{array}{l}99 \\
68 \\
51\end{array}$ & $\begin{array}{l}14 \\
15 \\
15\end{array}$ & $\begin{array}{l}14 \\
22 \\
29\end{array}$ \\
\hline
\end{tabular}

17 had defaulted, so that 51 women were no available for study. Of these, $15(29 \%)$ yielded yeasts on culture (table I); all the isolates were C. albicarfs Six of these 15 patients exhibited vulvovaginitis.

The effects of a course of tetracycline on tis vaginal yeast flora are summarized in table II. Aftê one week's treatment, 53 of 68 women $(78 \%$ remained yeast-negative and $10(15 \%)$ yeast-positive On the other hand, five women $(7 \%)$ initially yeastnegative were now yeast-positive. After two week $\overrightarrow{\overrightarrow{\mathbf{s}}^{3}}$ treatment, 35 of 51 women $(69 \%)$ remained yeas negative and seven (14\%) yeast-positive. Howevef, eight women $(16 \%)$ who were free from yeasts before treatment now yielded isolates, and one womag $(2 \%)$ had reverted from yeast-positive to yeastnegative during treatment.

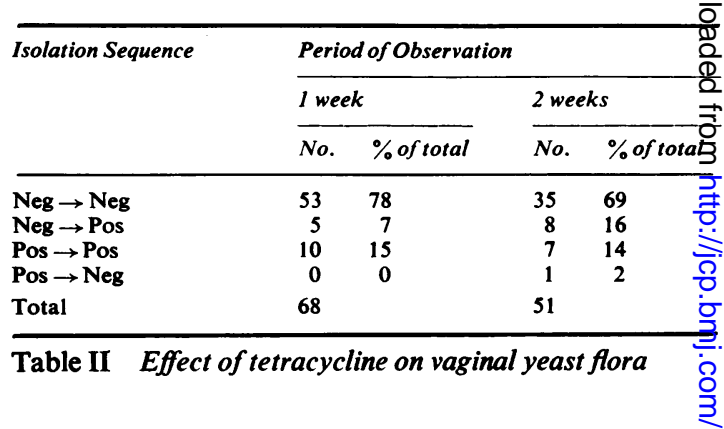

It is of interest that only a minority of patien who appeared to have become carriers of yeasts because of tetracycline therapy showed any evidence of vulvovaginitis, and this was rarely severe.

TREATMENT WITH MINOCYCLINE

A group of 105 women with NSGI was treated with $100 \mathrm{mg}$ minocycline twice daily. Side effects weremo noticeable than with tetracycline. At the end of the first week's treatment, 15 women had stopped taking the drug for this reason. A further 26 had defaulted, so that 64 were now available for study. Of these 64 women, 12 now yielded yeast isolates $(19 \%) ; 10 \%$ these were $C$. albicans and two were $T$. glabrat $\Phi_{.}$ Three of the 12 with positive cultures showed vulve vaginitis, as did two of 52 women with negative cultures. 


\begin{tabular}{llll}
\hline $\begin{array}{l}\text { Days after } \\
\text { Treatment }\end{array}$ & $\begin{array}{l}\text { No. } \\
\text { Attending }\end{array}$ & $\begin{array}{l}\text { No.withPositive } \\
\text { Cultures }\end{array}$ & $\%$ Positive \\
\hline 0 & 105 & 13 & 13 \\
7 & 64 & 12 & 19 \\
14 & 48 & 14 & 29 \\
\hline
\end{tabular}

Table III Vaginal yeast culture results before and after minocycline therapy

After the second week of observation three more women had stopped treatment because of side effects and a further 13 had defaulted, so that 48 were now available for study. Of these, $14(29 \%)$ yielded yeasts on culture; nine of the patients yielded C. albicans, three $T$. glabrata, one $C$. albicans together with $T$. glabrata, and one $C$. parapsilosis. Of the 14 patients with vaginal yeasts, four had vulvovaginitis, as did one of 34 patients with negative cultures (table III).

The effect of minocycline on the vaginal yeast flora is summarized in table IV; the overall effects are similar to those of tetracycline. After one week's treatment 50 of 64 women $(78 \%)$ remained yeastnegative and five $(8 \%)$ remained yeast-positive; seven women $(11 \%)$ initially yeast-negative were now yeast-positive and two (3\%) had reverted from yeast-positive to yeast-negative. After two weeks' treatment 32 of 48 women $(67 \%)$ remained yeastnegative and three $(6 \%)$ remained yeast-positive since their first attendance. However, 11 patients $(23 \%)$ who were free from yeasts before treatment now gave positive cultures and two $(4 \%)$ had reverted from yeast-positive to yeast-negative.

Again only a minority of women who developed a drug-induced mycosis had any clinical evidence of infection.

\begin{tabular}{|c|c|c|c|c|}
\hline \multirow[t]{3}{*}{ Isolation Sequence } & \multicolumn{4}{|c|}{ Period of Observation } \\
\hline & \multicolumn{2}{|c|}{ I week } & \multicolumn{2}{|c|}{2 weeks } \\
\hline & No. & $\%$ of total & No. & $\%$ of total \\
\hline $\begin{array}{l}\mathrm{Neg} \rightarrow \text { Neg } \\
\mathrm{Neg} \rightarrow \text { Pos } \\
\text { Pos } \rightarrow \text { Pos } \\
\text { Pos } \rightarrow \text { Neg }\end{array}$ & $\begin{array}{r}50 \\
7 \\
5 \\
2\end{array}$ & $\begin{array}{r}78 \\
11 \\
8 \\
3\end{array}$ & $\begin{array}{r}32 \\
11 \\
3 \\
2\end{array}$ & $\begin{array}{r}67 \\
23 \\
6 \\
4\end{array}$ \\
\hline Total & 64 & & 48 & \\
\hline
\end{tabular}

Table IV Effect of minocycline on vaginal yeast flora

\section{Discussion}

The appearance of vulvovaginitis during tetracycline therapy is of clinical importance; for this reason, and because of the ease of collecting vaginal specimens for yeast culture, we chose this area for study rather than the anal canal favoured by other investigators (Smits, Prior, and Arblaster, 1966).
Yeast isolates from the vagina were obtained before treatment from 27 of 204 women $(13 \%)$. The proportion of positive results was lower than in some other studies; for example, Oriel, Partridge, Denny, and Coleman (1972) recovered yeasts from $26 \%$ of a group of young women attending a department of venereology. This difference may be accounted for by variation in age, oral contraception and other factors which we did not investigate here. Like others (Oriel et al, 1972; Hurley, Leask, Faktor, and de Fonseka, 1973), we found $T$. glabrata to be the second commonest yeast isolated after $C$. albicans.

Both tetracycline and minocycline appear to have a definite effect on yeast isolation, the isolation rate being approximately doubled after a two-week oral course. There was no significant difference between minocycline and tetracycline in this respect, and our hopes that minocycline might be less liable to cause yeast overgrowth were not fulfilled. Perhaps the effect of minocycline on commensal bacteria leading to an alteration in vaginal yeast flora is of more importance than any direct inhibitory action of the antibiotic against yeasts.

It was of interest that only a minority of patients in whom tetracyclines had apparently caused an overgrowth of yeasts exhibited clinical evidence of yeast infection. Similarly, other workers (British Tuberculosis Association, 1968) have found that the proliferation of Candida in the bowel following the administration of tetracycline makes little difference to the frequency of side effects; in this study Candida was grown from rectal swabs in 37 and $38 \%$ respectively of those with and without gastrointestinal symptoms. The reasons for the appearance of symptoms and signs of genital mycosis in only some patients harbouring yeasts are obscure at present, and it may well be that the factors affecting the appearance of actual clinical disease in these patients are quite different from those causing simple yeast overgrowth.

We are grateful to Dr. D. W. R. Mackenzie, of the Mycological Reference Laboratory, London School of Hygiene and Tropical Medicine, for identifying yeasts other than $C$. albicans, and to Lederle Laboratories for financial support and for supplying the antibiotics used.

\section{References}

British Tuberculosis Association (1968). Comparison of side-effects of tetracycline and tetracycline plus nystatin: Report by the Clinical Trials Sub-committee. Brit. med. J., 4, 411-415.

Hurley, R., Leask, B. G. S., Faktor, J. A., and de Fonseka, C. I. (1973). Incidence and distribution of yeast species 
and Trichomonas vaginalis in the vagina of pregnant women. J. Obstet. Gynaec. Brit. Cwlth, 80, 252-257.

Mackenzie, D. W. R. (1962). Serum tube identification of Candida albicans. J. clin. Path., 15, 563-565.

Oriel, J. D., Partridge, B. M., Denny, M. J., and Coleman, J. C. (1972). Genital yeast infections. Brit. med. J., 4, 761-764.
Smits, B. J., Prior, A. P., and Arblaster, P. G. (1966) Incidence of Candida in hospital in-patients and the effects. of antibiotic therapy. Brit. med.J., 1, 208-210.

Waterworth, P. M. (1974). The effect of minocycline of Candida albicans. J. clin. Path., 27, 269-272.

Winner, H. I. and Hurley, R. (1964). Candida albicans, pp 72 and 185. Churchill. London.

\section{Reports and Bulletins prepared by the Association of Clinical Biochemist.}

The following reports and bulletins are published by the Association of Clinical Biochemists. They may be obtaine from The Publishing Department, British Medical Journal (ACB Technical Bulletins), B.M.A. House, Tavistocfs Square, London WC1H 9JR. Overseas readers should remit by British Postal or Money Order.

SCIENTIFIC REPORTS (price $£ 1 \cdot 00 / \$ 2.00$ each)

3 Automatic Dispensing Pipettes: an assessment of 35 commercial instruments September 1967 P. M. G. BROUGHTON, A. H. GOWENLOCK, G. M. WIDDOWSON, and K. A. AHLQUIST

4 An Evaluation of five Commercial Flame Photometers suitable for the Simultaneous Determination of Sodium and Potassium March 1970 P. M. G. BROUGHTON and J. B. DAWSON

SCIENTIFIC REVIEWS (price $£ 1 \cdot 00 / \$ 2.00$ each)

1 The Assessment of Thyroid Function March 1971 F. V. FLYNN and J. R. HOBBS

2 Renal Function Tests Suitable for Clinical Practice January 1972 F. L. MITCHELL, N. VEALL, and R. W. E. WATTS

TECHNICAL BULLETINS (price $£ 1.00 / \$ 2.00$ each)

9 Determination of Urea by AutoAnalyzer November 1966 RUTH M. HASLAM

11 Determination of Serum Albumin by AutoAnalyzer using Bromocresol Green October 1967 B. E. NORTHAM and G. M. WIDDowson

13 An Assessment of the Technicon Type II Sampler Unit March 1968 B. C. GRAY and G. K. MCGOWAN

14 Atomic Absorption Spectroscopy: an outline of its principles and a guide to the selection of instruments May 1968 J. B. DAWSON and P. M. G. BROUGHTON

15 A Guide to Automatic Pipettes (2nd edition) June 1968 P. M. G. BROUGHTON

16 A Guide to Automation in Clinical Chemistry May 1969 P. M. G. BROUGHTON

17 Flame Photometers: a comparative list of 17 instruments readily available in Britain August 1969 P. WIIDING

19 Spectrophotometers: a comparative list of low-priced instruments readily available in Britain May 1970 C. E. WILDE and P. SEWELL

20 Quantities and Units in Clinical Biochemistry June 1970 P. M. G. BROUGHTON
21 Filter Fluorimeters: A comparative list of 18 instru话 ments September 1970 H. BRAUNSBERG and S. so BROWN

22 Bilirubin Standards and the Determination of Bilirubi by Manual and Technicon AutoAnalyzer Methods January 1971 BARBARA BILLING, RUTH HASLAM, and N. WALD

23 Interchangeable Cells for Spectrophotometers and Fluorimeters September 1971 S. S. BROWN and A. PR GOWENLOCK

24 Simple Tests to Detect Poisons March 1972 B. va MEADE et al.

25 Blood Gas Analysers May 1972 R. DIxoN

26 Kits for Enzyme Activity Determination Septembe 1972 S. B. ROSALKI and D. TARLOW

27 Assessment of Pumps Suitable for Incorporation int Existing Continuous Flow Analytical Systems November 1972 A. FLECK et al.

28 Routine Clinical Measurements of Transferrin Human Serum September 1973 K. DIXON

29 Control Materials for Clinical Biochemistry (5t edition) September 1973 J. F. STEVENS

30 Notes on the Quality of Performance of Serum Cholesterol Assays September 1973 s. S. BROWN

31 Determination of Uric Acid in Blood and in Urines July 1974 R. W. E. WATTS

32 A Survey of Amino Acid Analyzers Readily Avain able in the United Kingdom September 1974 J. E CARLYLE and P. PURKISS

33 Definitions of some Words and Terms used if Automated Analysis November 1974 A. FLECK, ROBINSON, S. S. BROWN, and J. R. HOBBS

34 Measurement of Albumin in the Sera of Patien January 1975 LINDA SLATER, P. M. CARTER, and J. HOBBS

35 Investigation of the Validity of Temperature $\mathrm{Cog}$ rection Factors for Serum Aspartate and Alanine Trans aminases March 1975 S. B. ROSALKI et al. 